Pijper, A. \& Abraham, G. (1954). J. gen. Microbiol. 10, 452-456.

\title{
Wavelengths of Bacterial Flagella
}

\author{
By A. PIJPER \\ Institute for Pathology, University of Pretoria \\ AND G. ABRAHAM \\ Onderstepoort Laboratory, South Africa
}

\begin{abstract}
SUMMARY : In sunlight dark-ground microscopy the flagella of a packet of motile sarcina appear as a smooth tail. The tails often stiffen into helices of two different wavelengths, one being twice as long as the other. The short and the long wavelengths are identical in Sarcina ureae and $S$. agilis. This phenomenon of two wavelengths, one twice as long as the other, was also found, though less frequently, in certain other bacteria. Otherwise the wavelengths of the flagella of these bacteria appeared specific.
\end{abstract}

It has been claimed that bacterial flagella are not homologous (Pijper, $1949 a, b$; 1951; Pijper, Crocker, van der Walt \& Savage, 1953) but fall into different natural groups. It is therefore significant that the novel flagellar feature described here apparently is the exclusive property of one of these groups.

\section{MATERIALS AND METHODS}

We are indebted to Dr J. P. van der Walt, now of the South African Council for Scientific and Industrial Research, for isolating Sarcina ureae from local garden soil, and to Prof. Annelyse Winkler of Göttingen and Dr E. G. Pringsheim of the Botany School, Cambridge, for a strain of $S$. agilis, and of Caryophanon latum, respectively. An $\mathbf{H 9 0 1}$ culture of Salmonella typhi we owe to Dr A. Felix. For flagellar wavelengths of other bacteria we used photomicrographs published by others.

The two Sarcina and Caryophanon spp. were examined as agar cultures, the flagella being slightly thickened by precipitated agar without having their wavelengths affected (Pijper, 1949b). Similarly, Sal. typhi was suspended in $0.5 \%(\mathrm{w} / \mathrm{v})$ methylcellulose in saline.

The sunlight dark-ground microscope technique used was described by Pijper $(1946,1949 b)$. Flagellar measurements on the sarcina were made from dark-ground photomicrographs produced by a $\times 60$ Zeiss objective, and a Kontax camera, resulting in a magnification of $\times 300$. The negatives, through a photographic enlarger, were projected at a magnification of $\times 3000$ and the flagellar shapes traced with pencil on paper. The tracings were measured with a pair of compasses and a millimeter scale. Pl. 1, figs. 2-7, and Pl. 2, figs. 8-12, illustrate some of the flagella measured. Assuming that measurements were accurate to $0.3 \mathrm{~mm}$., actual wavelengths (distance from crest to crest) could be expressed with an accuracy of $0 \cdot 1 \mu$. 


\section{RESULTS}

\section{Wavelengths of flagella of sarcina}

Packets of S. ureae in sunlight dark-ground microscopy showed their flagella (word here used without prejudice) as a faint smooth tail (Pl. 1, fig. 1), very much like the fuzzy-looking tail previously described for Sal. typhi (Pijper, $1946,1949 b$ ). These tails changed their shape in various ways, but the most common change was a sudden stiffening into a helix (Pl. 1, figs. 2, 3). This transition did not directly affect the motility of the packet. Its causation remains obscure. It might happen to one of several packets in a field, or to most packets in a field. Older cultures showed it more often. After several days of growth most packets had these helical flagella, or the helices had broken off and were floating by themselves. Helices whether loose or still attached tended to combine. Lengthwise 'linking' is shown in Pl. 1, figs. 4-6. The regularity of the coils facilitated transverse 'packing', bringing about the more solid structures of Pl. 1, figs. 5 and 7. Entanglement of 'linked' and 'packed' helices caused pseudo-agglutination (Pl. 1, fig. 5). 'Packing', whilst increasing the width of the helices to a slight degree, did not affect wavelengths.

Gradually the impression was gained that $S$. ureae produced helices of two different wavelengths, and that the one wavelength was double the other. This is clear in Pl. 1, fig. 6, where examples of the two wavelengths are shown in one field, and in Pl. 1, fig. 7, where flagella of two wavelengths are accidentally linked up.

An investigation of $S$. agilis showed similar conditions. Faint fuzzy tails stiffened into helices of short wavelength (PI. 2, fig. 8) or long wavelength (P1. 2, fig. 9). Lengthwise linking of short-wavelength helices is shown in Pl. 2, fig. 10, and accidental linking of short and long wavelength flagella in Pl. 2, fig. 11. In Pl. 2, fig. 12, examples of the two wavelengths are seen in the same field. The fundamental wavelengths in $S$. ureae and $S$. agilis appeared the same. $S$. ureae habitually produced more helices of long wavelength than of short wavelength, and $S$. agilis did the opposite.

A large number of measurements seemed needed to decide what the relations really were. This was done as described above, the results are given in Table 1.

Table 1 allows the conclusion that the tails of both $S$. ureae and $S$. agilis change into helices of two kinds, and that in both organisms the one kind of helix has a wavelength of $1 \cdot 6 \mu$, and the other a wavelength of $3 \cdot 2 \mu$, thus confirming the impression that one wavelength is double the other.

\section{Observations on other bacteria}

The occurrence of helical flagella of two wavelengths, one double the other, was looked for in other bacteria. Our collection of dark-ground photomicrographs of Sal. typhi showed several instances, of which Pl. 2, figs. 13 and 14, are examples. The two wavelengths are about $1 \cdot 1$ and $2 \cdot 2 \mu$. In Caryophanon latum straight fuzzy tails can also stiffen into helical structures; Pl. 2, 
fig. 15, shows two helical flagella of different wavelength attached to one cell, and one wavelength is double the other.

Table 1. Statistical analysis of measured wavelengths of flagella of S. ureae and S. agilis

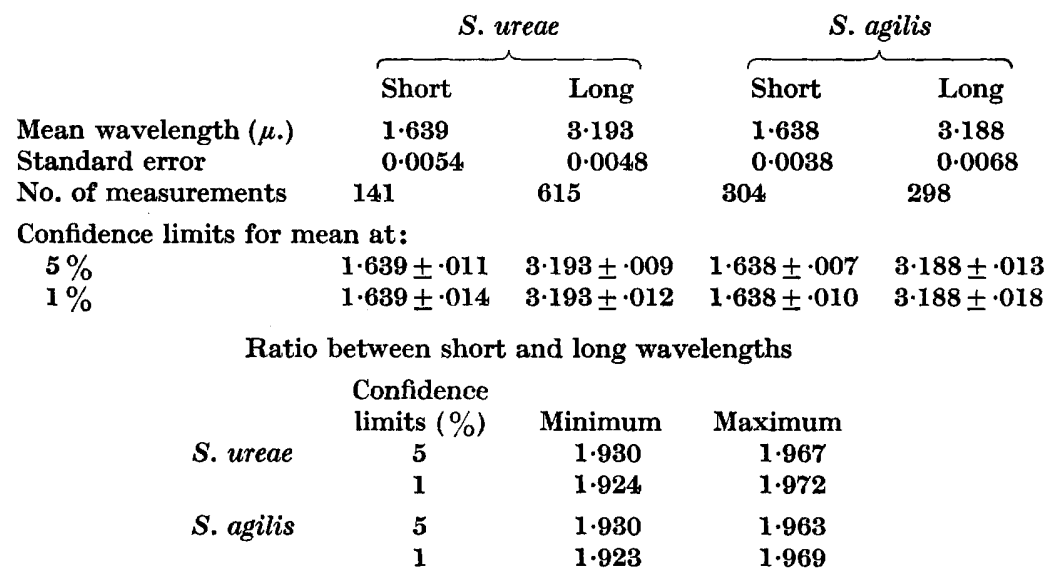

Transitions from smooth tails into helical flagella were described for Proteus vulgaris (Pijper, 1946, 1949b) and for Bacillus cereus (Pijper, 1949b). At that time no helices of different wavelengths were noticed or photographed. Pietschmann (1942) published a dark-ground photomicrograph of $B$. cereus in $1 \%(\mathrm{w} / \mathrm{v})$ tragacanth solution in water where in one field two different wavelengths were visible in stiffened helical flagella. The wavelengths were approximately 2.4 and $1.2 \mu$. Her only comment was that flagella of $\boldsymbol{B}$. cereus which had stopped moving could show narrow or wide windings. She also showed similar photomicrographs of two bundles of flagella of Pr. vulgaris, one having a wavelength double the other, without comment. Neumann (1928) published, also without comment, two photomicrographs of bundles of helical flagella of Pr. vulgaris suspended in $5 \%(\mathrm{w} / \mathrm{v})$ gum arabic in water; the wavelength of one was $c .0 \cdot 9 \mu$, and of the other $c .1 \cdot 9 \mu$.

\section{DISCUSSION}

The hard horny excrescences called flagella in spirilla have nothing in common with the soft and fuzzy-looking structures called flagella in sarcina, Sal. typhi, Pr. vulgaris, B. cereus, C. latum and allied bacteria. In keeping with this, the flagella of Spirillum spp. do not occur with two different wavelengths; their very structure would seem to exclude this (Pijper, 1949a, b, 1951; Pijper et al. 1953). This constitutes a further argument why bacterial flagella cannot be regarded as homologous. Bacterial flagella are generally supposed to have a wavy, spiral (or better, helical) appearance. Flagellar wavelength has not been studied much, probably because the traditional dry preparations were regarded as misleading. Leifson (1951), however, although he only dealt with dried and stained preparations, suggested that perhaps wavelengths might be 
more important than length. Leifson \& Hugh (1954) since found $0.62 \mu$ the average wavelength of twenty-five fixed and stained flagella of a pseudomonad. On this unusually short wavelength they wished to found a new species. Our findings suggest a need for measurements on wet preparations and on larger numbers. Reichert (1909) from dark-ground observations in colloid solutions concluded that in Sal. typhi the pitch of the screw-like flagella was $2.5 \mu$, and of Pr. vulgaris $2 \mu$. In two motile sarcinas he estimated the pitch in dead individuals to be sometimes 2 or $1.8 \mu$, but usually $3 \mu$. Weibull(1949) precipitated shakenoff flagella of $\boldsymbol{P r}$. vulgaris and $\boldsymbol{B}$. subtilis with ammonium sulphate and described the wet flagella as having a period of $2 \mu$. in $\operatorname{Pr}$. vulgaris and $2.5 \mu$. in B. subtilis. Later (1950) he measured the precipitated flagella of ten strains of Proteus spp. and confirmed his value of $2 \mu$. From this he concluded that a definite spiral period is a characteristic feature of bacterial flagella. Neither author had noticed the occurrence, to which we here call attention, of the two wavelengths, one twice the other. Their figures therefore require correction. With this important reservation we confirm that flagellar wavelength is a characteristic feature. Its practical value for classification, however, is further limited by the necessity to perform many measurements on wet preparations, and by the fact that the range of available wavelengths is very limited. Leifson's (1951) observation of a strain of Sal. wichita which dissociated into two variants, one showing flagella twice the wavelength of the other, has no bearing on our phenomenon. The two kinds of wavelength were not seen by him in one and the same culture but only in two separate cultures, and moreover in fixed and stained preparations which easily give rise to artefacts. Also, our strain of Sal.typhi $\mathbf{H} 901$ can hardly contain two variants. The central coiled filament of the flagellum of $B$. brevis indicated in the electron photographs of de Robertis \& Franchi (1951) and the helical fine structure of the flagella of a motile diphtheroid appearing in the electron photographs of Starr \& Williams (1952) appear to be of rather too different an order to cause the phenomenon we have described here. Our phenomenon may find its explanation in the molecular structure of this particular kind of flagellum.

Our thanks are due to the South African Council for Scientific and Industrial Research for providing the services of a research assistant and the use of laboratory equipment.

\section{REFERENCES}

Leifson, E. (1951). Staining, shape, and arrangement of bacterial flagella. J. Bact. $62,377$.

Leifson, E. \& Hugh, R. (1954). A new type of polar monotrichous flagellation. J. gen. Microbiol. 10, 68.

NeumanN, F. (1928). Die Sichtbarmachung von Bakteriengeisseln am lebenden Objekt im Dunkelfeld. Zbl. Bakt. (1. Abt. Orig.), 109, 143.

Pietschmann, K. (1942). Über die Begeisselung der Bakterien. Arch. Mikrobiol. 12, 377.

PiJPer, A. (1946). Shape and motility of bacteria. J. Path. Bact. 58, 325.

PiJper, A. (1949a). The flagella of Spirillum volutans. J. Bact. 57, 111.

PiJPer, A. $(1949 b)$. Bacterial surface, flagella and motility. In The Nature of the Bacterial Surface. Symp. Soc. gen. Microbiol. 1, 144. 
PiJPer, A. (1951). Bactèrial flagella. Nature, Lond. 168, 749.

Pijper, A., Crocker, C. G., Walt, J. P. van der \& Savage, N. (1953). Flagellum and motility of Spirillum serpens. J. Bact. 65, 628.

Reichert, K. (1909). Über die Sichtbarmachung der Geisseln und die Geisselbewegung der Bakterien. Zbl. Bakt. (1. Abt. Orig.), 51, 1.

Robertis, E. DE \& Franchi, C. M. (1951). Electron microscope observation of the fine structure of bacterial flagella. Exp. Cell Res. 2, 295.

Starr, M. P. \& Williams, R. C. (1952). Helical fine structure of flagella of a motile diphtheroid. J. Bact. 63, 701.

WeIBUld, C. (1949). Morphological studies on salt precipitated bacterial flagella. Ark. Kemi, 1, 21.

Weibull, C. (1950). Investigations on bacterial flagella. Acta chem. scand. 4, 268.

\section{EXPLANATION OF PLATES}

\section{Plate 1}

Fig. 1. Fast moving small packet of $S$. ureae, with tail ; $\times 1000$.

Fig. 2. Small packet of $S$. ureae, tail stiffened into helix of long wavelength; $\times 1500$.

Fig. 3. Small packet of $S$. ureae, tail stiffened into helix of short wavelength; $\times 1500$.

Fig. 4. Several helices of short wavelength of $S$. ureae linked up lengthwise; $\times 1500$.

Fig. 5. Transverse 'packing' and lengthwise 'linking' of helices of long wavelength of S. ureae; $\times 1500$.

Fig. 6. Helical flagella of both long and short wavelength of $S$. ureae in same field, several helices linked up lengthwise; $\times 1500$.

Fig. 7. 'Packed' helix of short wavelength linked up accidentally with helix of long wavelength, both of $S$. ureae; $\times 1500$.

\section{Plate 2}

Fig. 8. Small packet of $S$. agilis, tail stiffened into helix of short wavelength; $\times 1500$.

Fig. 9. Large packet of $S$. agilis, tail stiffened into helix of long wavelength; $\times 1500$.

Fig. 10. Long stretch of helices of short wavelength of $S$. agilis linked up lengthwise; $\times 1500$.

Fig. 11. Helices of long and short wavelength of $S$. agilis, accidentally linked up; $\times 1500$.

Fig. 12. Helices of long and short wavelength of S. agilis in one field; $\times 1500$.

Fig. 13. Sal. typhi with helix of short wavelength; $\times 1500$.

Fig. 14. Sal. typhi with numerous helices of long wavelength; $\times 1500$.

Fig. 15. Caryophanon latum with one helix of short wavelength and one helix of long wavelength; about $\times 600$. 
Journal of General Microbiology, Vol. 10, No. 3
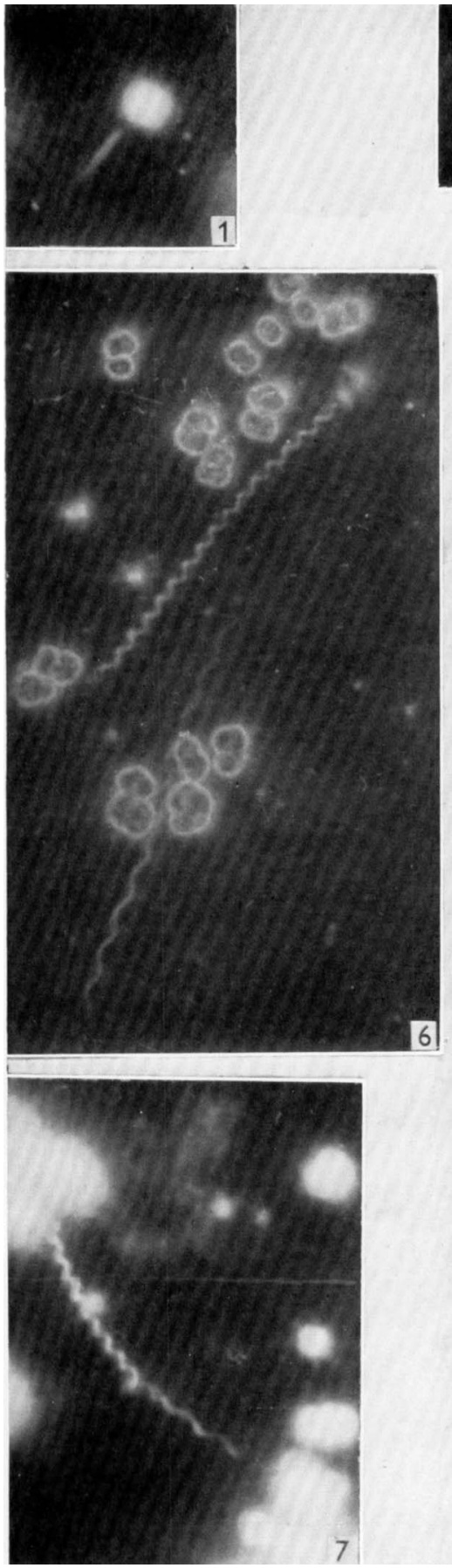
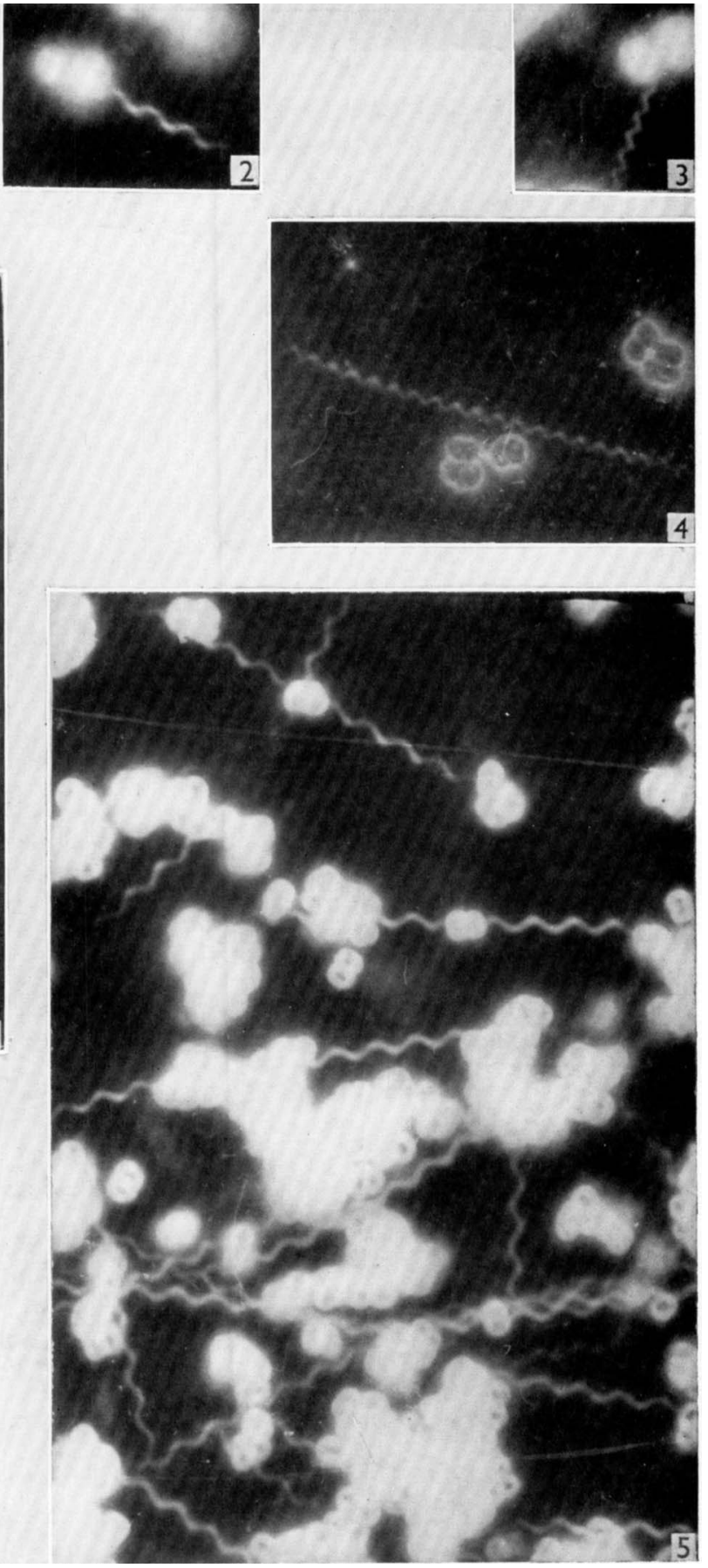

A. Pijper \& G. Abraham-Wavelingths of bacterial flagella. Plate 1 
Journal of General Microliology, Vol. 10, No. 3
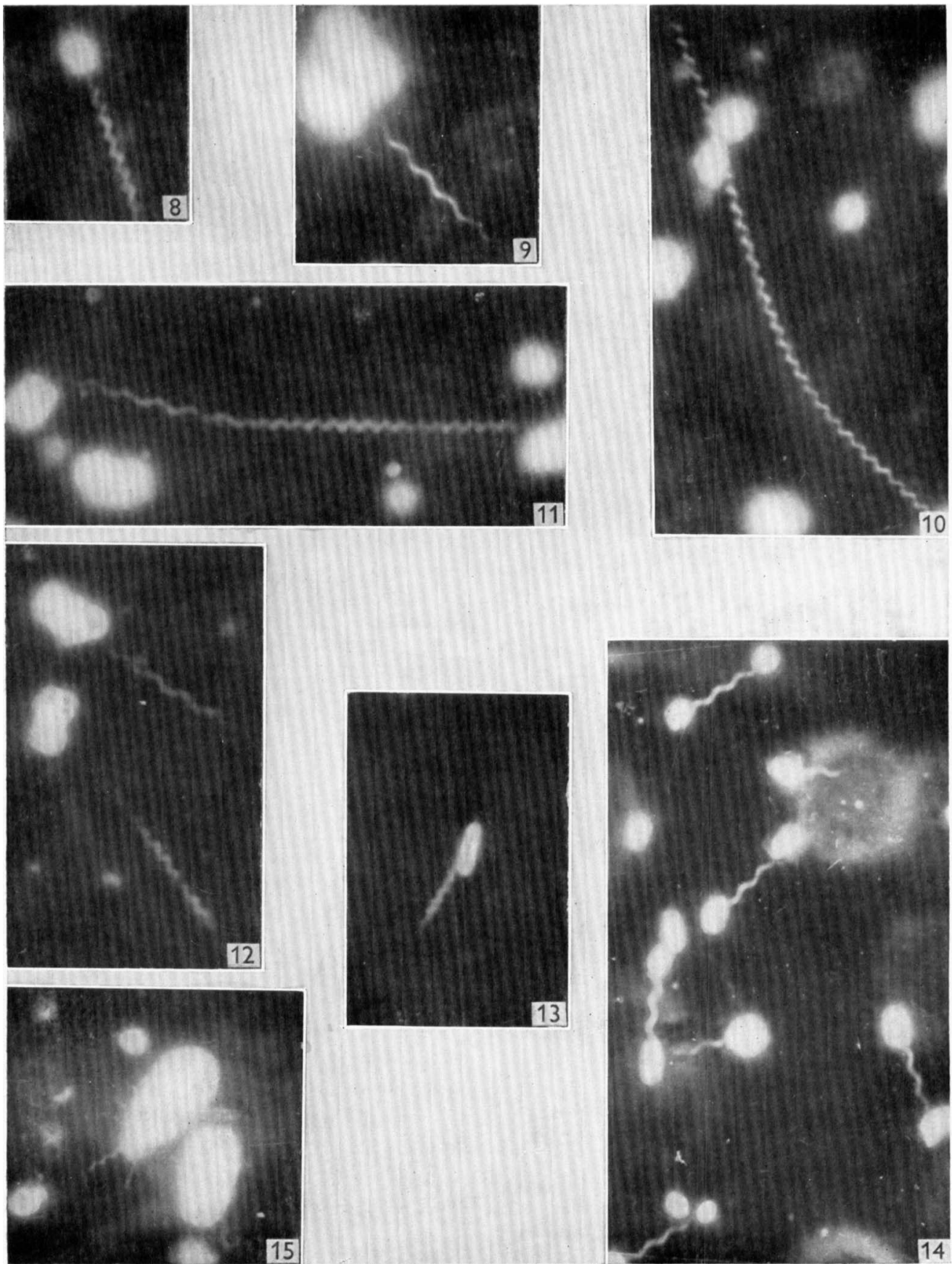

A. Pijper \& G. Abraham--Wavelengths of bacterial flagella. Plate 2 